\title{
'Chronomics' in ICU: circadian aspects of immune response and therapeutic perspectives in the critically ill
}

\author{
Vasilios Papaioannou ${ }^{1,2^{*}}$, Alexandre Mebazaa' ${ }^{1}$, Benoît Plaud ${ }^{1}$ and Matthieu Legrand ${ }^{1}$
}

\author{
* Correspondence: \\ papabil69@gmail.com \\ ${ }^{1}$ Department of Anesthesiology and \\ Critical Care and Burn Unit, Hôpitaux \\ Universitaire St-Louis-Lariboisière, \\ Assistance Publique-Hôpitaux de \\ Paris, University of Paris Diderot, \\ U942 INSERM, Paris 75475, France \\ ${ }^{2}$ Intensive Care Unit, \\ Alexandroupolis University Hospital, \\ Democritus University of Thrace, \\ School of Medicine, Dragana, \\ Alexandroupolis 68100, Greece
}

\begin{abstract}
Complex interrelations exist between the master central clock, located in the suprachiasmatic nuclei of the hypothalamus, and several peripheral clocks, such as those found in different immune cells of the body. Moreover, external factors that are called 'timekeepers', such as light/dark and sleep/wake cycles, interact with internal clocks by synchronizing their different oscillation phases. Chronobiology is the science that studies biologic rhythms exhibiting recurrent cyclic behavior. Circadian rhythms have a duration of approximately $24 \mathrm{~h}$ and can be assessed through chronobiologic analysis of time series of melatonin, cortisol, and temperature. Critically ill patients experience severe circadian deregulation due to not only the lack of effective timekeepers in the intensive care unit (ICU) environment but also systemic inflammation. The latter has been found in both animal and human studies to disrupt circadian rhythmicity of all measured biomarkers. The aims of this article are to describe circadian physiology during acute stress and to discuss the effects of ICU milieu upon circadian rhythms, in order to emphasize the value of considering circadian-immune disturbance as a potential tool for personalized treatment. Thus, besides neoplastic processes, critical illness could be linked to what has been referred as 'chronomics': timing and rhythm. In addition, different therapeutic perspectives will be presented in association with environmental approaches that could restore circadian connection and hasten physical recovery.
\end{abstract}

Keywords: Circadian rhythm; Cortisol; Critical illness; Cytokines; Melatonin; Pineal gland; Sepsis

\section{Review}

Introduction

Circadian rhythms refer to self-sustained fluctuations with a period of approximately (circa) 1 day (diem) in various physiological processes. Circadian rhythmicity is observed for many hormones in circulation (i.e., corticosteroids) as well as for circulating immune cells and cytokines [1,2]. Ten circadian clock genes have been identified in human peripheral tissues so far, including Period (Per-1-3), Crypto-chrome (Cry-1 and Cry-2), Clock, and Bmal1, which coordinate with the master clock located in the suprachiasmatic nuclei ( $\mathrm{SCN})$ of the anterior hypothalamus [3].

In mammals, the circadian system is composed of many individual, tissue-specific clocks with their phase being controlled by the master circadian pacemaker of SCN

\section{严 Springer}


[1]. SCN neurons control clock genes throughout the body by controlling two major communication channels, the endocrine system and the autonomic nervous system (ANS). The recent discovery of a novel third type of retinal photoreceptor, other than rods and cones, provided evidence of a pathway mediating non-visual effects of light [4]. Subsequent signals are directed towards SCN neurons through the retinohypothalamic tract and synchronize them to the day/light cycle. Furthermore, connections of SCN with other hypothalamic structures allow the master clock to synchronize other clock genes in the body $[5,6]$. Additionally, through sympathetic nerve projections, SCN output signals induce the release of a major internal synchronizer, the pineal substance melatonin (Figure 1) [5,7].

Melatonin is synthesized by the pineal gland upon $\beta$ adrenoreceptor stimulation of pinealocytes, increased during sleepiness, and decreased during wakefulness, and it conveys the information of nighttime to the organism. In healthy humans, melatonin secretion starts between 9:00 p.m. and 11:00 p.m., reaching peak serum levels between 1:00 a.m. and 3:00 a.m. ( $>40 \mathrm{pg} / \mathrm{mL})$ and then falling to low baseline values between 7:00 a.m. and 9:00 a.m $(<7 \mathrm{pg} / \mathrm{mL})$ [8,9]. It also plays the role of an endogenous

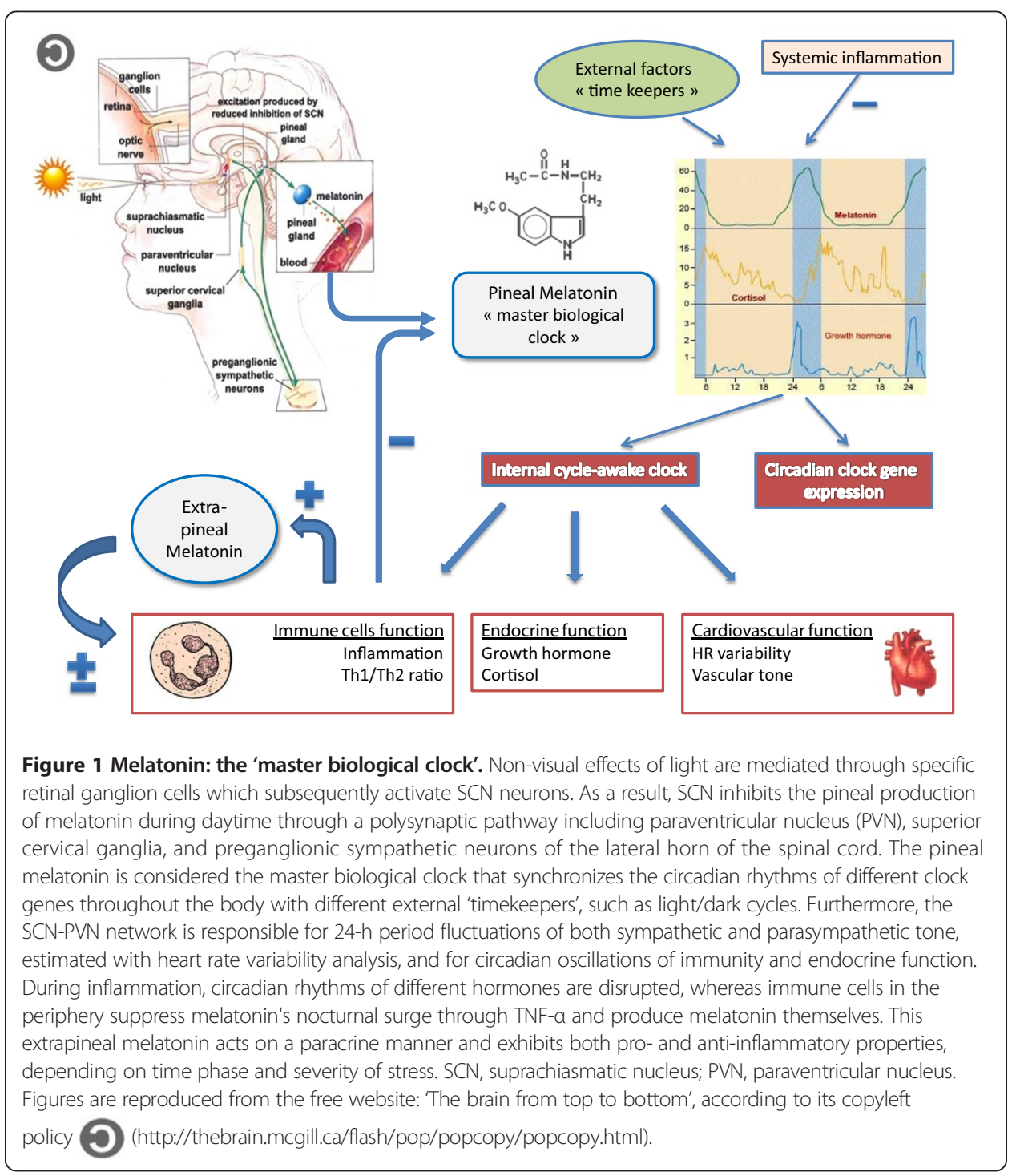


synchronizer, which is able to stabilize circadian rhythms and maintain their mutual phase relationships. Furthermore, its rhythm is involved in the regulation of the sleep/ wake cycle, sleep structure, and more generally in the temporal organization of immunity [1,5]. The last is considered as an effective component of 'predictive homeostasis' since nearly all organisms have developed mechanisms for anticipating environmental changes to optimize their survival [1,2]. In this respect, temporal organization of immune response maximizes it at the time of the day that is needed most, since exposure to microbial pathogens depends on intrinsic 24-h rhythms of the host (activity, feeding). Moreover, immune modulation by the ANS, which also displays a diurnal rhythmicity, further supports the notion of immune regulation by light/dark cycle $[1,6]$. Melatonin is also considered an active anti-inflammatory molecule due to the inhibition of tumor necrosis factor $\alpha$ (TNF- $\alpha$ ) production $[9,10]$. In addition, melatonin has an extrapineal source since different gastrointestinal cells synthesize melatonin, which has a peripheral activity (e.g., protection against reperfusion injury in gut mucosa), through its antioxidant properties [11].

Circadian rhythms are also synchronized and maintained by different phase relationships to external factors. These rhythms persist with an identical period (light/dark, sleep/ wake) or are different throughout a day. These external factors are also called 'timekeepers' and are considered as effective modulators for the circadian oscillator (e.g., light, feeding, ambient temperature, and stress) [12].

Several studies have demonstrated that there is a circadian rhythmicity of different components of the immune system [1,13-15]. Moreover, it has been suggested that circadian regulation of immunity is necessary for temporal coincidence of all its different molecular steps [13-15]. Thus, circadian oscillations of lymphocyte proliferation, antigen presentation, and cytokine gene expression appear coordinated via SCN output signals. Additionally, the number of most immune cells reaches maximal values during the night and is lowered after arousal [1].

\section{Circadian physiology and inflammation Experimental data}

Different pro-inflammatory cytokines, such as TNF- $\alpha$ and interleukin-6 (IL-6), may cross the blood-brain barrier at leaky points (the circumventricular organs (CVO)) and induce a 'sickness behavior', associated with decreased amplitude of circadian rhythmicity, such as loss of sleep/wake cycle $[1,16]$.

Many studies have found that the susceptibility of mice to lipopolysaccharide (LPS) and TNF- $\alpha$-induced lethality varied significantly throughout the day, depending on the time of administration [17-20]. Moreover, immune response upon LPS challenge, such as cytokine production [21] or toll-like receptor 9 (TLR9) expression [22], has been shown to display circadian rhythmicity, depending on time of LPS administration. Chronic inflammation can also affect SCN output by reducing amplitude and average spiking frequency of SCN neurons [23,24]. In addition, LPS exposure has been found to suppress mRNA expression levels of different clock genes, in both animal [25] and human studies [26,27]. However, melatonin and cortisol circadian rhythms were not affected by LPS (Table 1). It has been suggested that centrally regulated hormones' circadian rhythmicity and peripheral clock gene expression are independently regulated during sepsis, reflecting an uncoupling between central and peripheral oscillators during systemic inflammation [28]. 
Table 1 Immune-circadian connection: experimental studies

\begin{tabular}{|c|c|c|}
\hline Author & Study design & Major outcome \\
\hline Haldberg et al. [17] & $\begin{array}{l}\text { Susceptibility of mice to Escherichia } \\
\text { coli endotoxin-induced lethality }\end{array}$ & $\begin{array}{l}\text { Lethality varied significantly throughout } \\
\text { the day, depending on the time when mice } \\
\text { were challenged }\end{array}$ \\
\hline Hrushesky et al. [18] & $\begin{array}{l}\text { Effect of time of TNF-a } \\
\text { administration on lethal toxicity } \\
\text { in mice }\end{array}$ & $\begin{array}{l}\text { Nine-fold variation of lethality being } \\
\text { greatest during night and particularly } \\
\text { before awakening }\end{array}$ \\
\hline Keller et al. [21] & $\begin{array}{l}\text { Splenocytes from mice, isolated at } \\
\text { various times of the day, were } \\
\text { challenged with LPS }\end{array}$ & $\begin{array}{l}\text { Circadian rhythmicity of TNF-a and IL- } 6 \\
\text { secretion was found. More than } 8 \% \text { of } \\
\text { the peritoneal macrophage transcriptome } \\
\text { oscillates in a circadian function } \\
\text { autonomically and depends on time } \\
\text { of LPS challenge }\end{array}$ \\
\hline Silver et al. [22] & $\begin{array}{l}\text { Toll-like receptor } 9 \text { (TLR9) expressed } \\
\text { in peritoneal macrophages were } \\
\text { estimated for circadian rhythmicity } \\
\text { in a mouse model of sepsis }\end{array}$ & $\begin{array}{l}\text { Vaccination with TLR9 ligand as adjuvant } \\
\text { at the time of enhanced TLR9 } \\
\text { responsiveness induced an improved } \\
\text { adaptive immune response many } \\
\text { weeks later. Moreover, disease severity } \\
\text { was dependent on the timing of sepsis } \\
\text { induction, coinciding with daily changes } \\
\text { in TLR9 expression }\end{array}$ \\
\hline Kwak et al. [24] & $\begin{array}{l}\text { Study of the long-term effects of } \\
\text { INF-y on SCN neurons by treating } \\
\text { dispersed rat SCN neurons with } \\
\text { INF-y for a 4-week period }\end{array}$ & $\begin{array}{l}\text { Firing of SCN neurons and rhythmic } \\
\text { expression of clock gene Perl exhibited } \\
\text { a lower average spiking frequency with } \\
\text { reduced amplitude and an irregular } \\
\text { firing pattern, in relation with controls }\end{array}$ \\
\hline Okada et al. [25] & $\begin{array}{l}\text { LPS effects on mRNA expression } \\
\text { of clock genes in rats }\end{array}$ & $\begin{array}{l}\text { mRNA expression levels of different } \\
\text { clock genes, such as Per } 1 \text { and Per } 2, \\
\text { both in the liver and SCN neurons on } \\
\text { day } 1 \text {, were suppressed with an } \\
\text { expression nadir between } 10 \text { and } \\
14 \text { h post-challenge. Subsequently, } \\
\text { recovery was noted on day 2, whereas } \\
\text { controls exhibited a robust circadian profile }\end{array}$ \\
\hline Boivin et al. [26] & $\begin{array}{l}\text { Estimation of clock gene oscillations } \\
\text { in human blood mononuclear cells } \\
\text { derived from three human volunteers }\end{array}$ & $\begin{array}{l}\text { Presence of circadian oscillations of } \\
\text { Per land Per } 2 \text { genes }\end{array}$ \\
\hline Haimovich et al. [27] & $\begin{array}{l}\text { Assessment of clock gene alterations } \\
\text { upon LPS administration in peripheral } \\
\text { human blood leucocytes, after } \\
\text { challenging them with in vivo } \\
\text { endotoxin or saline, either at } \\
\text { 09:00 a.m or 09:00 p.m. }\end{array}$ & $\begin{array}{l}\text { LPS induced a profound suppression } \\
\text { of all clock gene expression by } 80 \% \text { to } \\
90 \% \text {, between } 13 \text { and } 17 \mathrm{~h} \text { post-perfusion, } \\
\text { whereas IL- } 6 \text { and TNF-a returned to } \\
\text { baseline within } 6 \mathrm{~h} \text {. However, melatonin } \\
\text { and cortisol circadian rhythms were not } \\
\text { affected by LPS challenge }\end{array}$ \\
\hline \multirow[t]{2}{*}{ Pontes et al. [32] } & \multirow{2}{*}{$\begin{array}{l}\text { Colostrum samples for measuring } \\
\text { tumor necrosis factor a (TNF-a) and } \\
\text { melatonin content were collected } \\
\text { from } 18 \text { normal delivered mothers in } \\
\text { the morning, and diurnal and nocturnal } \\
\text { melatonin levels in colostrum from } \\
\text { healthy puerperae and mothers with } \\
\text { mastitis were compared }\end{array}$} & $\begin{array}{l}\text { Suppression of nocturnal melatonin rise } \\
\text { in mothers with mastitis was highly } \\
\text { correlated with increased tumor necrosis } \\
\text { factor a secretion. }\end{array}$ \\
\hline & & $\begin{array}{l}\text { On the other hand, stimulated, but not } \\
\text { quiescent, immune-competent cells } \\
\text { secreted in the colostrum produced } \\
\text { melatonin in vitro. In addition, this } \\
\text { production ceased after bacteria killing }\end{array}$ \\
\hline Cruz-Machado et al. [33] & $\begin{array}{l}\text { Effects of LPS on melatonin production } \\
\text { in rat pineal cultures }\end{array}$ & $\begin{array}{l}\text { Shutdown of melatonin production } \\
\text { through TNF-a induction of NF-kB in } \\
\text { pineal microglial cells }\end{array}$ \\
\hline
\end{tabular}

The immune-pineal axis A continuous communication between the pineal gland and the immune response has been suggested to exist, defining the 'immune-pineal axis' [29]. Thus, pineal melatonin nocturnal secretion enhances Th1/Th2 ratio within low 'chronobiotic' levels (nM-pM range) and inhibits at the same time both rolling and 
adherence of leucocytes to the endothelial layer, decreasing unnecessary inflammatory response [29-31]. Furthermore, extrapineal melatonin produced by local immunecompetent cells acts in a paracrine manner as anti-inflammatory mediator in higher concentrations (mM range) [32-34]. Thus, it seems that in the early phase of inflammation, the body does not receive circadian information through the hormonal arm.

Markus et al. [35] have postulated that systemic inflammation activates the nuclear factor kappa B (NF-kB) pathway through LPS/TLR4 signaling at the level of pinealocytes and suppresses central melatonin nocturnal secretion, enhancing migration of immune cells at the site of injury. At the same time, different inflammatory mediators upregulate melatonin production in peripheral macrophages. This extrapineal tissue melatonin has been described as 'immune buffer' since it seems to play a dual role [36]. During acute stress, it acts as immunostimulant, improving bacterial phagocytosis, and subsequently, it enhances recovery phase by inducing production of anti-inflammatory cytokines. However, during an exacerbated inflammatory response, melatonin acts mainly as an anti-inflammatory molecule.

Corticosteroids may also affect melatonin pineal production [37,38]. Thus, by inhibiting the NF-kB pathway in the pineal gland, they can restore its nocturnal rise [37] and enhance its production in a bell-shaped manner [38]. However, they can also decrease the activity of $\mathrm{N}$-acetyltransferase (NAT) which is a key enzyme in the biosynthetic pathway of melatonin and hence inhibit its pineal production [39]. Finally, increased cortisol response to stress has been correlated with decreased amplitude of its own circadian rhythm [40].

In summary, different experimental studies confirm the existence of circadian oscillations of the immune response, which can be significantly suppressed by LPS. In addition, mortality seems to depend on time of LPS administration (Table 1).

\section{Circadian rhythm profiles and critical illness}

Circadian output assessment Periods and modeling variability of different biological time series that reflect circadian output, such as melatonin and cortisol, are assessed via cosinor analysis [41]. Briefly, this technique fits a cosine function of a fixed anticipated period to the data and approximates the following equation to experimental data, using the least squares method for minimization:

$$
Y_{t}=M+A^{*} \cos \left(2 \pi / \mathrm{TAU}^{*} t+\Phi\right)
$$

where, $M$ is the midline estimating statistic of rhythm (MESOR), the mean level of oscillation; $A$ is the amplitude, the extent of oscillation from the MESOR or half of the total oscillation; $\pi$ is 3.14159; TAU is the chosen period; $t$ is a temporal fraction of the cycle, an instant of the whole revolution; and $\Phi$ (phi) is the acrophase, lag from a defined reference time point (e.g., local midnight when the fitted period is $24 \mathrm{~h}$ ) of the crest time in the cosine curve fitted to the data (Figure 2).

Except for serum melatonin, its urine metabolite 6-sulfatoxymelatonin (6-SMT) [10] and core body temperature (CBT) [42] are accepted biomarkers of circadian rhythm in critically ill patients.

Circadian disruption in critically ill patients Circadian rhythms are disrupted by illness and intensive care unit (ICU) environment, associated with patient care 


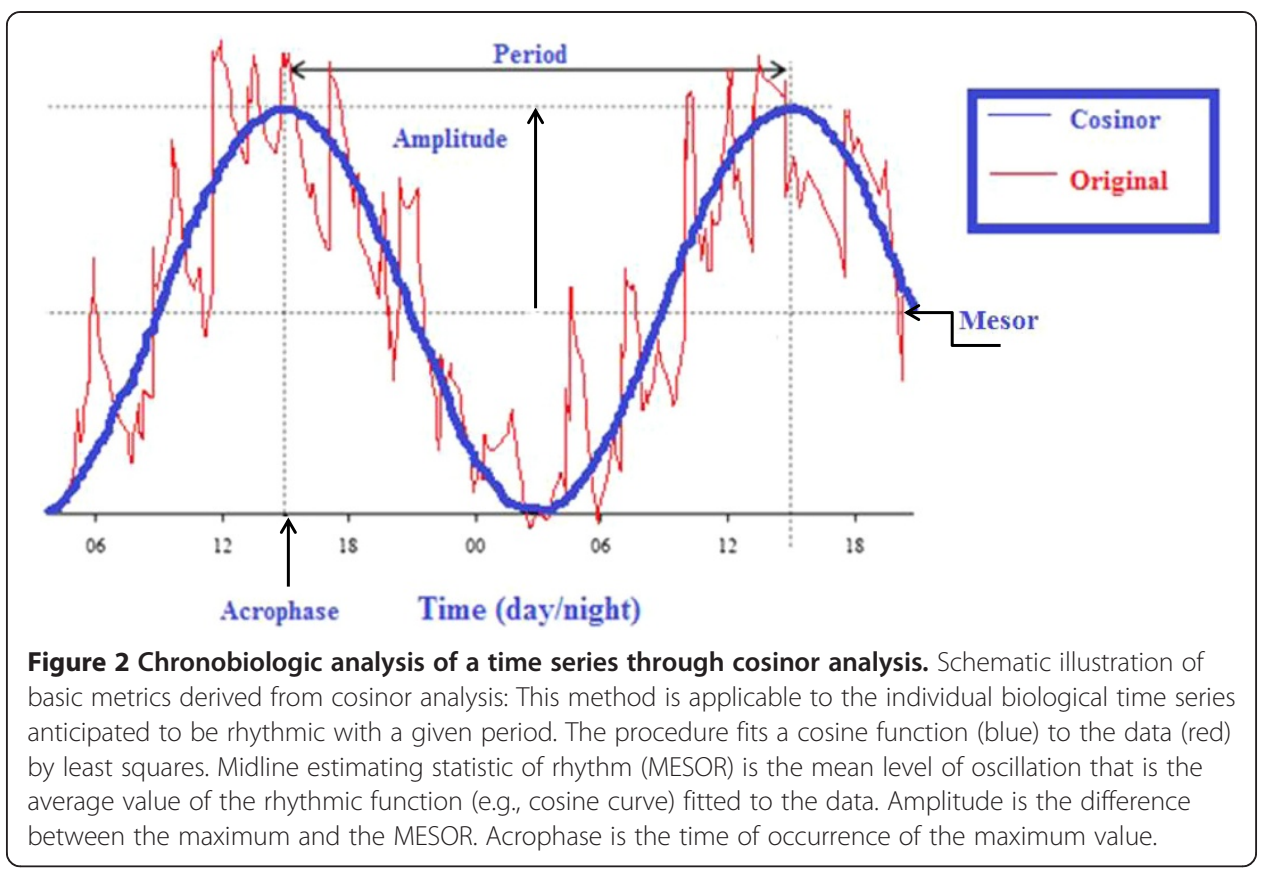

interactions and unregulated light/dark patterns. Different clinical studies have demonstrated that a significant proportion of critically ill patients display long-term sleep disturbance and metabolism, suggesting a contribution of biological rhythm alterations [43,44].

In this respect, many authors have investigated circadian biomarkers in different groups of patients during their ICU stay, in order to assess a potential circadian dysfunction during critical illness (Table 2) [45-51]. Such misalignment occurs when there is an alteration between cycle frequency and phase in two or more rhythms [5,12]. Its clinical significance has been established in different settings, since it has been shown to induce a prediabetic condition in healthy humans [52] and symptoms associated with heart failure in animal models of cardiovascular disease [53]. Furthermore, misaligning the cortisol rhythm has been shown to induce profound cardiovascular and renal disease sequel, which was subsequently reversed by light exposure therapy in hamsters [54].

Only a few investigators have evaluated circadian alterations during sepsis (Table 2) [55-59]. Mudlinger et al. [55] assessed in ICU circadian disruption in 17 septic patients versus 7 non-septic and 21 controls. Urinary 6-SMT, measured at 4-h intervals over a 24-h period, exhibited significant loss of circadian rhythmicity with no daytime decline in septic versus non-septic patients and controls, respectively.

Recently, Li et al. [59] studied for $24 \mathrm{~h} 11$ septic and 11 non-septic ICU patients and measured during the first day of admission plasma levels of melatonin, TNF- $\alpha$, and IL6 and messenger RNA levels of circadian genes Cry-1 and Per-2. The authors found altered circadian rhythm of melatonin secretion, decreased expression of both Cry- 1 and Per-2, and high levels of TNF- $\alpha$ and IL-6 in septic patients. They also showed that the suppression of peripheral circadian genes was independent of the melatonin rhythm.

In conclusion, Li et al. [59] confirmed that during acute phase of sepsis in humans, there is an uncoupling of the central master clock and peripheral tissue-specific clock genes, associated with pro-inflammatory cytokine production. Moreover, acrophase 
Table 2 Circadian disruption in critically ill patients: clinical studies

\begin{tabular}{lll}
\hline Author & Study design & Major outcome \\
\hline Tweedie et al. [45] & Retrospective study for characterizing core & 80\% of all patient days had a significant \\
& $\begin{array}{l}\text { body temperature (CBT) 24-h profiles of } \\
\text { circadian rhythm with erratic acrophases } \\
\text { 15 ICU patients }\end{array}$ & and normal amplitudes
\end{tabular}

Nuttall et al. [46]

Retrospective study assessing clinical significance of circadian rhythms in patients with $(\leq 17)$ and without $(n=120)$ ICU psychosis, by comparing for $24 \mathrm{~h}$ the time of both temperature and urine output nadir

Olofsson et al. [47]

Study of melatonin levels in both blood and urine in 8 critically ill patients under sedation and mechanical ventilation

Both groups had altered circadian rhythms, and although all 'patient days' had a significant rhythm, $83 \%$ of those days had abnormal cosinor-derived parameters

Frisk et al. [48]

Study of 6-SMT and urine cortisol in 16 patients, treated in the ICU of two regional hospitals

The circadian rhythm of melatonin release was abolished in all but 1 patient, whereas no correlation was found between melatonin levels and level of sedation

Hyposecretion of 6-SMT during mechanical ventilation, increase upon adrenergic stimulation, overall high cortisol excretion and, finally, a disturbed diurnal rhythm of both these hormones in $75 \%$ of all patients

Paul and Lemmer [49] Measurement of CBT every hour and The 24-h circadian profiles of all measured plasma cortisol and melatonin levels every variables were significantly disturbed, with $2 \mathrm{~h}$ for $24 \mathrm{~h}$, in 13 sedated ICU patients following surgery or respiratory failure and 11 patients with brain injury

no physiological day-night rhythm in both groups of patients in relation with healthy controls, whereas circadian rhythm alterations were more pronounced in patients with brain injuries

Pina et al. [50]

Prospective analysis of hourly CBT and 4-h interval urine cortisol, melatonin, and 6 -SMT profiles in 8 burn patients and 14 controls for $24 \mathrm{~h}$ in three sessions, occurring between ICU days 1 to 3 day 10 , and days 20 to 30

Gazendam et al. [51] Investigation of circadian rhythm disruption in a general ICU population assessed using CBT profiles over a 48-h period in 21 patients

Mudlinger et al. [55] Circadian alterations in 17 septic patients versus 7 non-septic subjects and 21 controls, in the ICU

Perras et al. [56]

Measurement of single nocturnal melatonin concentration (NMC) in 302 patients during their first night in ICU

Bagci et al. [57]

Nocturnal plasma melatonin and 6-SMT urine concentrations were measured in 23 septic and 13 non-septic pediatric ICU patients

Circadian rhythms of all measured

variables were abolished in all patients in relation with controls. Burn ICU patients displayed significantly higher MESORS of CBT, urine melatonin, 6-SMT, and cortisol compared with the control group, during the three sessions of measurements. 24-h circadian profiles were restored within a 30-day period

Acrophase shift in all cases. Acute Physiology and Chronic Health Evaluation (APACHE) III score was predictive of circadian misplacement

Urinary 6-SMT exhibited circadian rhythmicity in only 1 of 17 septic patients versus 6 of 7 in non-septic patients and 18 of 23 in normal controls. MESORS appeared slightly increased, phase amplitudes were markedly lower, and acrophase occurred later in septic patients. On the contrary, in both non-septic patients and controls, 6-SMT exhibited a circadian rhythm

Analysis of the whole study population did not reveal any correlation between single melatonin measurement and APACHE II score, but in 14 patients with severe sepsis, an inverse correlation was found

The NMC during septic shock was increased in relation with no shock states. There was no difference for nocturnal and total 6-SMT excretion between septic patients with and without septic shock and non-septic patients. Nocturnal and total 6-SMT excretion was significantly lower in septic patients with than in septic patient without liver dysfunction. Sedation and mechanical ventilation did not affect melatonin excretion 
Table 2 Circadian disruption in critically ill patients: clinical studies (Continued)

\begin{tabular}{|c|c|c|}
\hline Gehlbach et al. [58] & $\begin{array}{l}\text { Assessment of sleep/wake regulation and } \\
\text { circadian rhythmicity for } 24 \text { h, through } \\
\text { 1-h interval urine measurements of 6-SMT, } \\
\text { in } 22 \text { mechanically ventilated patients } \\
\text { with different diagnoses of ICU admission }\end{array}$ & $\begin{array}{l}\text { The 24-h temporal profile of 6-SMT } \\
\text { exhibited a phase delay. There was no } \\
\text { difference between patients with and } \\
\text { without sepsis and no correlation } \\
\text { between APACHE II score and 6-SMT } \\
\text { amplitude }\end{array}$ \\
\hline \multirow[t]{2}{*}{ Li et al. [59] } & $\begin{array}{l}11 \text { septic and } 11 \text { non-septic patients in } \\
\text { ICU. Peripheral blood was drawn at 4-h } \\
\text { intervals during the first day of admission }\end{array}$ & \multirow{2}{*}{$\begin{array}{l}\text { The melatonin secretion acrophase } \\
\text { occurred earlier in septic patients } \\
\text { compared with non-septic patients. } \\
\text { Melatonin MESORS tended to be higher in } \\
\text { the septic group. Both Cry-1 and Per-2 } \\
\text { expression were decreased, while TNF-a } \\
\text { and IL-6 expression were increased in } \\
\text { septic patients, reaching a peak at } 6: 00 \text { p. } \\
\text { m, which was consistent with the altered } \\
\text { rhythm of melatonin secretion. Suppression } \\
\text { of peripheral circadian genes was } \\
\text { independent of the melatonin rhythm }\end{array}$} \\
\hline & $\begin{array}{l}\text { Plasma levels of melatonin, TNF-a, IL-6, } \\
\text { and messenger RNA levels of circadian } \\
\text { genes Cry-1 and Per- } 2 \text { were analyzed }\end{array}$ & \\
\hline
\end{tabular}

shift exhibited an advance rather than a delay in septic patients, contrary to what was found in the study of Mudlinger that included patients with at least 1 week stay in the ICU [55]. We suppose that at the early stages of sepsis, the inverse relation between melatonin and pro-inflammatory cytokines that was clearly shown in different animal models is more evident [35]. However, during the late stages, medications, such as catecholamines and varying levels of sedation $[48,60]$, could also alter circadian rhythms, since both morphine [60] and benzodiazepines [48] have been shown to induce NAT activity and enhance in a dose-dependent manner daytime production of melatonin [10]. In addition, mechanical ventilation [48] and ICU milieu [61-63] may further disrupt circadian variations, limiting accurate assessment of immune-circadian connectivity.

ICU environment and circadian output disruption ICU milieu can be considered as a particular stress trigger for the internal circadian clock. Exposure to persistent environmental light has been recognized as a serious concern in the ICU [61-63]. However, different authors have found that light failed to influence circadian rhythms in healthy subjects [64] and in septic critically ill patients under controlled ventilation [65,66], suggesting that sepsis per se could decrease sensitivity to light exposure.

Drugs are potential confounders of immune-circadian connectivity in critically ill patients. In this respect, both opioids [50] and benzodiazepines [67] may alter melatonin production. Additionally, increased sympathetic tone and use of vasopressors during septic shock could theoretically enhance melatonin excretion. However, sympathetic reuptake of norepinephrine [68] and poor responsiveness of human pineal gland to circulating catecholamines [69] protect against the inappropriate increase in pineal melatonin production.

Another significant stressor of circadian rhythms in sedated patients is the sleep/wake cycle disruption. Different studies have confirmed that the majority of these patients experience either sleep deprivation and/or sleep fragmentation [43,44,58,70]. It has been suggested that the dispersion of episodic 'sleep-like states' could be responsible for the reduced amplitude and acrophase delay of urine 6-SMT that was also noticed in healthy subjects $[58,71]$. Nevertheless, it seems that sleep per se remains a weak timekeeper in humans without a concomitant change in the light/dark cycle [72]. Finally, delirium has been implicated as a pathologic state modifying melatonin excretion in 
elderly conscious medical patients [10,73]. At the same time, melatonin circadian deregulation has been associated with neurotransmitter alterations and subsequent delirium in septic patients $[74,75]$. However, it remains unclear if it is the quantity or the rhythm profile of melatonin that is related to delirium occurrence [10].

\section{Potential therapeutic implications}

Duboule [76] and Halberg [77] introduced the term 'chronomics', time and rhythm, for describing circadian regulation of animal development and chronotherapy in different disease states. Evidence from observational studies is growing that circadian disruption contributes to the development of cancer [76,78]. So, it has been suggested that melatonin could be beneficial in cancer treatment when administered at chronobiologically determined optimum times of the day [79].

Administration of melatonin has been found in both animals $[79,80]$ and one human study in neonates [81] to reduce hyperinflammatory response during sepsis. In addition, it has been shown that melatonin exhibits an in vitro antimicrobial activity against multi-drug resistant Gram-negative and Gram-positive bacteria due to free iron binding [82] and furthermore can protect kidney grafts from ischemia-reperfusion injury [83]. Moreover, prolonged nighttime melatonin administration lowers blood pressure in hypertensive subjects [84], since SCN neurotransmitter content and transmission are suppressed during hypertension [85]. Finally, in two randomized placebo-controlled trials, melatonin [86] and a synthetic analog [87] were found to decrease incidence of delirium in elderly medical patients, but did not affect its duration or severity. However, intention-to-treat analysis was not possible in the first trial because of lost to follow-up patients.

Nevertheless, many aspects remain unresolved. Thus, prior knowledge of the circadian profile of the patient is needed in order to design a personalized melatonin dose and duration of treatment, as well as chronobiologically determined optimum time of administration, since a circadian rhythmicity has been found for both pharmacokinetics and pharmacodynamics of different drugs, such as antibiotics [88]. Furthermore, melatonin excretion can be altered by liver and renal injury or by circadian modulation of hepatic function and glomerular filtration rate $[10,89]$. In this respect, different timekeepers, such as light or medications, have been used in cancer or psychiatric disorders, on the right time and order and at a specific phase of the circadian cycle [78,90]. Similarly, different 'rhythm therapies' could be scheduled for ICU patients, following the kairos principle (right time of the day) instead of chronos (time in general) [76,78]. Moreover, introduction of additional timekeepers and excitation of the biological system with ultradian short-period rhythms, such as light or art therapy, have been found to enhance long-period fluctuations of melatonin by excitation, coupling, and resonance [91]. As a result, a restored circadian rhythmicity has been noticed in patients with sleep disorders and subjects with jet lag [91]. Such effects may also enlarge the circadian cycle of heart rate variability (HRV), which is connected with sleep quality and ANS dysfunction [78,92].

It has been postulated that entrained and synchronized circadian rhythms better prepare the physiology of an individual to anticipate normal cycles of energy demand in order to optimize adaptive regulation [93]. This 'self-adaptation' behavior is transformed into a 'self-defense' response during stress [31], explaining results from different 
studies. Thus, pro-inflammatory cytokines shut down melatonin's nocturnal surge in the acute phase, whereas exacerbated or chronic inflammation upregulates pineal production through anti-inflammatory mediators, such as corticosteroids [36,38]. However, there is a lot of heterogeneity in different studies due to interspecies differences or time and severity of inflammatory insult, prompting a standardization of experimental protocols for translating results in the ICU setting.

Since severity of disease varies across the day and night $[20,94]$ and the temperature curve might exhibit an inverted pattern (febris inversa) in different infections, such as tuberculosis where fever is higher in the morning than in the evening, we suggest that future studies should assess differences in terms of circadian profiles, between patients suffering from an inflammatory episode that occurs at different time points of a 24-h period. Moreover, and since light unresponsiveness of $\mathrm{SCN}$ has been found in septic patients $[65,66]$, we suppose that in this particular group, possible circadian misalignment might reflect mainly individualized immune-circadian connections. In that case, it would be interesting to study if different circadian biomarkers correlate significantly with the Sequential Organ Failure Assessment (SOFA) score of severity of illness and predict mortality better than SOFA. In addition, ICU environmental profiles could be correlated with trajectories of circadian biomarkers, and different environmental approaches to patient care, such as 'virtual darkness' by shortening the day length, could be designed and tested to promote more rapid attainment of circadian rhythms [95]. Finally, restoring circadian light/dark cycle might improve immune function through enhanced melatonin production, in the context of reduced energy availability associated with critical illness, as is currently observed in lower mammals during the winter [95].

Except for clinical researchers, basic scientists could also benefit from chronobiological analytic tools in order to design experimental studies and assess treatment effects in different septic models. It has been recognized that some of the reasons for negative results in different clinical trials in septic patients [96], despite encouraging results from preclinical studies, are the use of animal models that do not adequately mimic human sepsis [97]. Furthermore, misinterpretation of preclinical data or adoption of different experimental protocols has been considered as a contributing factor for this discrepancy [97]. In this respect, the use of 'higher fidelity animal models' has been suggested in order to increase the clinical relevance of experimental research [98]. Nevertheless, we would like to highlight the importance of assessing immune-circadian connectivity as a further step for translating basic science results into successful randomized controlled trials. Thus, different models should evaluate clock gene expression in immune-competent cells upon LPS challenge at standardized time points and in different environmental settings (i.e., light manipulation) [99], whereas clock gene knockout animals could also be used for assessing circadian-immune disconnection. Finally, new statistical methods, such as EUCLIS (EUCLOCK Information System, an EU FP6 project) [100] could be tested for analyzing the genome, the proteome, and the metabolome.

\section{Conclusions}

As was suggested by Haldberg et al. [77], 'in biologic time series that are dense and sufficient long the characteristics of rhythms and trends can be quantified as elements of structures called chronoms'. 'Microscopy-in-time' chronobiology studies cycles in 
biological time series with mechanisms embedded in living matter, whereas 'telescopyin-time' chronomics assesses their alignment with environmental cues [101]. Thus, chronobiologic surveillance could be implemented in the ICU, serving a better understanding of biologic complexity in critical illness and, subsequently, an individualized optimization of treatment. In this respect, vascular variability anomalies (VVAs) estimated with chronomics, such as heart rate and blood pressure variability, have been recognized as significant risk factors in patients with cardiovascular diseases [102]. Similarly, reduced HRV has been repeatedly demonstrated in patients with sepsis and organ dysfunction [28]; however, chronobiologic analysis has not been performed so far.

In the context of negative results from different clinical studies in septic patients [96], we suggest that individual rhythm analysis might add significant value to the caring of critically ill. Thus, continuous monitoring of different biosignals, such as electrocardiogram (ECG), could detect diurnal variations in HRV and patterns of change specific for each patient and each pathophysiological state, creating an individual profile of 'physiomarkers' that could be used as both a diagnostic and therapeutic monitoring tool in everyday clinical practice. In addition, circadian aspects of pharmacokinetics and both liver and renal function could be considered in daily treatment, in order to increase efficiency and/or reduce adverse effects of medical therapy on a personalized basis. Finally, future clinical trials should assess circadian aspects of immunity and therapeutics for evaluating treatment effects. In this respect, adoption of different modeling techniques and design of in silico studies could be applied towards understanding inflammation and translate computational systems biology approaches in sepsis research to clinical relevance [103].

\footnotetext{
Abbreviations

ANS: autonomic nervous system; APACHE: Acute Physiology and Chronic Health Evaluation; CBT: core body temperature; CVO: circumventricular organs; EUCLOCK: Entrainment of the circadian clock; ECG: electrocardiograph; EU FP6: European

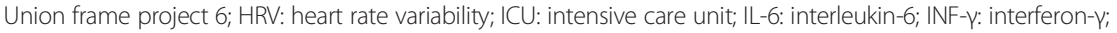
LPS: lipopolysaccharide; MESOR: midline estimating statistic of rhythm; NAT: N-acetyltransferase; NMC: nocturnal melatonin concentration; PVN: paraventricular nucleus; SCN: suprachiasmatic nucleus; 6-SMT: 6-sulfatoxymelatonin; SOFA: Sequential Organ Failure Assessment; TLR: toll-like receptor; TNF-a: tumor necrosis factor a; WA: vascular variability anomalies.
}

Competing interests

The authors declare that they have no competing interests.

\section{Authors' contributions}

VP conceived and wrote the review. AM, BP, and ML helped with literature research and editing of the manuscript. All authors read and approved the final manuscript.

Received: 4 February 2014 Accepted: 8 April 2014

Published: 14 May 2014

\section{References}

1. Esquifino Al, Cano P, Jimenez-Ortega V, Fernandez-Mateos P, Cardinali DP (2007) Neuro-endocrine-immune correlates of circadian physiology: studies in experimental models of arthritis, ethanol feeding, aging, social isolation and calorie restriction. Endocr 32:1-19

2. Webster JI, Tonelli L, Sternberg EM (2002) Neuroendocrine regulation of immunity. Annu Rev Immunol 20:125-163

3. Kusanagi H, Hida A, Satoh K (2008) Expression profiles of 10 circadian clock genes in human peripheral blood mononuclear cells. Neurosci Res 61:136-142

4. Brainard GC, Hanifin JP, Greeson JM, Byrne B, Glickman G, Gerner E, Rollag MD (2001) Action spectrum for melatonin regulation in humans: evidence for a novel circadian photoreceptor. J Neurosci 21(16):6405-6412

5. Golombek DA, Rosenstein RE (2010) Physiology of circadian entrainment. Physiol Rev 90:1063-1102

6. Buijs RM, la Fleur SE, Wortel J, Van Heyningen C, Zuiddam L, Mettenleiter TC, Kalsbeek A, Nagai K, Niijima A (2003) The suprachiasmatic nucleus balances sympathetic and parasympathetic output to peripheral organs through separate preautonomic neurons. J Comp Neurol 464(1):36-48

7. Antle MC, Silver R (2005) Orchestrating time: arrangements of the brain circadian clock. Trends Neurosci 28:145-151

8. Pevet P, Challet E (2011) Melatonin: both master clock output and internal time-giver in the circadian clocks network. J Physiol 105:170-182

9. Brzezinski A (1997) Melatonin in humans. N Engl J Med 336:186-195 
10. Bourne RS, Mills GH (2006) Melatonin: possible implications for the post-operative and critically ill patient. Intensive Care Med 32:371-379

11. Bubenik GA (2002) Gastrointestinal melatonin: localization, function, and clinical relevance. Dig Dis Scie 47:2336-2348

12. Aschoff J (1960) Exogenous and endogenous components in circadian rhythms. Cold Spring Symp Quant Biol 25:11-28

13. Arjona A, Sarkar DK (2005) Circadian oscillations of clock genes, cytolytic factors, and cytokines in rat NK cells. J Immunol 174:7618-7624

14. Mazzoccoli G, Sothern RB, Greco A, Pazienza V, Vinciquerra M, Liu S, Cai Y (2011) Time-related dynamics of variation in core clock gene expression levels in tissues relevant to the immune system. Int J Immunopathol Pharmacol 24(4):869-879

15. Dimitrov S, Lange T, Tieken S, Fehm HL, Born J (2004) Sleep associated regulation of T helper $1 / T$ helper 2 cytokine balance in humans. Brain Behav Immun 18(4):341-348

16. Dantzer R (2006) Cytokine, sickness behavior, and depression. Neurol Clin 24(3):441-460

17. Haldberg F, Johnson EA, Brown BW, Bittner JJ (1960) Susceptibility rhythm to E. coli endotoxin and bioassay. Proc Soc Exp Biol Med 103:142-144

18. Hrushesky WJ, Langevin T, Kim YJ, Wood PA (1994) Circadian dynamics of tumor necrosis factor alpha (cachectin) lethality. J Exp Med 180(3):1059-1065

19. Smolensky MH, Halberg F, Sargent FS (1972) Chronobiology of the life sequence. In: Ogata SLK, Yoshimura H (ed) Advances in climatic physiology. Igaku Shoin, Tokyo

20. Hrushesky WJ, Wood PA (1997) Circadian time structure of septic shock: timing is everything. J Infect Dis 175(5):1283-1284

21. Keller M, Mazuch J, Abraham U, Eom GD, Herzog ED, Volk HD, Kramer A, Maier B (2009) A circadian clock in macrophages controls inflammatory immune responses. Proc Natl Acad Sci USA 106:21407-21412

22. Silver AC, Arjona A, Walker WE, Fikrig E (2012) The circadian clock controls toll-like receptor 9-mediated innate and adaptive immunity. Immunity 36(2):251-261

23. Lundkvist GB, Robertson B, Mhlanga JD, Rottenberg ME, Kristensson K (1998) Expression of an oscillating interferon-gamma receptor in the supra-chiasmatic nuclei. Neuroreport 9:1059-1063

24. Kwak Y, Lundkvist GB, Brask J, Davidson A, Menaker M, Kristensson K, Block GD (2008) Interferon- $y$ alters electrical activity and clock gene expression in suprachiasmatic nucleus neurons. J Biol Rhythms 23(2):150-159

25. Okada K, Yano M, Doki Y, Azama T, Iwanaga H, Miki H, Nakayama M, Miyata H, Takiguchi S, Fujiwara Y (2008) Injection of LPS causes transient suppression of biological clock genes in rats. J Surg Res 145(1):5-12

26. Boivin DB, James FO, Wu A, Cho-Park PF, Xiong H, Sun ZS (2003) Circadian clock genes oscillate in human peripheral blood mononuclear cells. Blood 102(12):4143-4145

27. Haimovich B, Calvano J, Haimovich AD, Calvano SE, Coyle SM, Lowry SF (2010) In vivo endotoxin synchronizes and suppresses clock gene expression in human peripheral blood leucocytes. Crit Care Med 38(3):751-758

28. Godin PJ, Buchman TG (1996) Uncoupling of biological oscillators: a complementary hypothesis concerning the pathogenesis of multiple organ dysfunction syndrome. Crit Care Med 24:1107-1116

29. Markus RP, Ferreira ZS, Fernandes PACM, Cecon E (2007) The immune-pineal axis: a shuttle between endocrine and paracrine melatonin sources. Neuro-immunomodulation 14:126-133

30. Skwarlo-Sonta K, Majewski P, Markowska M, Oblap R, Olszanka B (2003) Bidirectional communication between the pineal gland and the immune system. Can J Physiol Pharmacol 81:342-349

31. Lotufo CM, Yamashita CE, Farksy SH, Markus RP (2006) Melatonin effect on endothelial cells reduces vascular permeability increase induced by leukotriene B4. Eur J Pharmacol 534:258-263

32. Pontes GN, Cardoso EC, Carneiro-Sampaio MM, Markus RP (2006) Injury switches melatonin production source from endocrine (pineal) to paracrine (phagocytes) - melatonin in human colostrum and colostrum phagocytes. J Pineal Res 41:136-141

33. Da Silveira C-MS, Pinato L, Tamura EK, Carvalho-Sousa CA, Markus RP (2012) Glia-pinealocyte network: the paracrine modulation of melatonin synthesis by tumor necrosis factor (TNF). PloS ONE 7(7):e40142. doi:10.1371/journal. pone. 0040142

34. Da Silveira C-MS, Carvalho-Sousa CE, Tamura EK, Pinato L, Cecon E (2010) TLR4 and CD14 receptors expressed in the rat pineal gland triggers NFKB pathway. J Pineal Res 49:183-192

35. Markus RP, Ceson E, Pires-Lapa MA (2013) Immune-pineal axis: Nuclear factor kB (NF-kB) mediates the shift in the melatonin source from pinealocytes to immune competent cells. Int J Mol Sci 14:10979-10997

36. Carrillo-Vico A, Lardone PJ, Alvarez-Sanchez N, Rodriguez-Rodriguez A, Guerrero JM (2013) Melatonin: buffering the immune system. Int J Mol Sci 14:8638-8683

37. Lopes C, Mariano M, Markus RP (2001) Interaction between the adrenal and the pineal gland in chronic experimental inflammation induced by BCG in mice. Inflamm Res 1:6-11

38. Ferreira ZS, Fernandez PA, Duma D, Assreuy J, Avellar MC, Markus RP (2005) Corticosterone modulates noradrenaline-induced melatonin synthesis through inhibition of nuclear factor kappa B. J Pineal Res 3:182-188

39. Yuwiler A (1989) Effects of steroids on serotonin-N-acetyltransferase activity of pineals in organ culture. J Neurochem 52:46-53

40. Venkataraman S, Munoz R, Candido C, Witchel SF (2007) The hypothalamic-pituitary-adrenal axis in critical illness. Rev Endocr Metab Disord 8:365-373

41. Bingham C, Arbogast B, Guillaume GC, Lee JK, Halberg F (1982) Inferential statistical methods for estimating and comparing cosinor parameters. Chronobiologia 9:397-439

42. Weinert W, Waterhouse J (2007) The circadian rhythm of core temperature: effects of physical activity and aging Physiol Behav 90:246-256

43. Freedman NS, Gazandam J, Levan L, Pack Al, Scwab RJ (2001) Abnormal sleep/wake cycles and the effect of environmental noise on sleep disruption in the intensive care unit. Am J Respir Crit Care Med 163:451-457

44. Gabor JY, Cooper AB, Crombach SA, Lee B, Kadikar N, Bettger HE, Hanly PJ (2003) Contribution of the intensive care unit environment to sleep disruption in mechanically ventilated patients and healthy subjects. Am J Respir Crit Care Med 167:708-715

45. Tweedie IE, Bell CF, Clegg A, Campbell IT, Minors DS, Waterhouse JM (1989) Retrospective study of temperature rhythms of intensive care patients. Crit Care Med 17(11):1159-1165 
46. Nuttall GA, Kumar M, Murray MJ (1998) No difference exists in the alteration of circadian rhythm between patients with and without intensive care unit psychosis. Crit Care Med 26(8):1351-1355

47. Olofsson K, Alling C, Lundberg D, Malmros C (2004) Abolished circadian rhythm of melatonin secretion in sedated and artificially ventilated intensive care patients. Acta Anaesthesiol Scand 48:679-684

48. Frisk U, Olsson J, Nylen P, Hahn RG (2004) Low melatonin excretion during mechanical ventilation in the intensive care unit. Clin Sci 107:47-53

49. Paul T, Lemmer B (2007) Disturbance of circadian rhythms in analgosedated intensive care unit patients with and without craniocerebral injury. Chronobiol Int 24(1):45-61

50. Pina G, Brun J, Tissot S, Claustrat B (2010) Long-term alteration of daily melatonin, 6-sulfatoxymelatonin, cortisol and temperature profiles in burn patients: a preliminary report. Chronobiol Int 27(2):378-392

51. Gazendam JAC, Van Dongen HPA, Grant DA, Freedman NS, Zwaveling JH, Schwab RJ (2013) Altered circadian rhythmicity in patients in the ICU. Chest 144(2):483-489

52. Scheer FA, Hilton MF, Mantzoros CS, Shea SA (2009) Adverse metabolic and cardiovascular consequences of circadian misalignment. Proc Natl Acad Sci USA 106(11):4453-4458

53. Young ME (1985) Anticipating anticipation: pursuing identification of cardiomyocyte circadian clock function. J Appl Physiol 107(4):1339-1347

54. Martino TA, Oudit GY, Herzenberg AM, Tata N, Koletar MM, Kabir GM, Belsham DD, Backx PH, Ralph MR, Sole MJ (2008) Circadian rhythm disorganization produces profound cardiovascular and renal diseases in hamsters. Am J Physiol Regul Integr Comp Physiol 294(5):1675-1683

55. Mundigler G, Delle-Karth G, Koreny M, Zehetgruber M, Steindl-Munda P, Marktl W, Fertl L, Siostrzonek P (2002) Impaired circadian rhythm of melatonin secretion in sedated critically ill patients with severe sepsis. Crit Care Med 30:536-540

56. Perras B, Kurowski V, Dodt C (2006) Nocturnal melatonin concentration is correlated with illness severity in patients with septic disease. Intensive Care Med 32:624-625

57. Bagci S, Yildizdas D, Horoz OO, Reinsberg J, Bartmann P, Mueller A (2011) Use of nocturnal melatonin concentration and 6-sulfatoxymelatonin excretion to evaluate melatonin status in children with severe sepsis. J Pediatr Endocrinol Metab 24(11-12):1025-1030

58. Gehlbach BK, Chapotot F, Leproult R, Whitmore H, Poston J, Pohlman M, Miller A, Pohlman AS, Nedeltcheva A, Jacobsen JH, Hal JB, Van Cauter E (2012) Temporal disorganization of circadian rhythmicity and sleep-wake regulation in mechanically ventilated patients receiving continuous intravenous sedation. Sleep 35(8):1105-1114

59. Li CX, Liang DD, Xie GH, Cheng BL, Chen QX, Wu SJ, Wang JL, Cho W, Fang XM (2013) Altered melatonin secretion and circadian gene expression with increased proinflammatory cytokine expression in early-stage sepsis patients. Mol Med Rep 7(4):1117-1122

60. Esposti D, Esposti G, Lissoni P, Parravicini L, Fraschini F (1988) Action of morphine on melatonin release in the rat. J Pineal Res 5:35-39

61. Meyer TJ, Eveloff SE, Bauer MS, Schwartz WA, Hill NS, Millman RP (1994) Adverse environmental conditions in the respiratory and medical ICU settings. Chest 105(4):1211-1216

62. Dennis CM, Lee R, Woodard EK, Szalaj JJ, Walker CA (2010) Benefits of quiet time for neuro-intensive care patients. J Neurosci Nurs 42(4):217-224

63. Carlson DE, Chiu WC (2008) The absence of circadian cues during recovery from sepsis modifies pituitaryadrenocortical function and impairs survival. Shock 29(1):127-132

64. Bojkowski CJ, Aldhous ME, English J, Franey C, Poulton AL, Skene DJ, Arendt J (1987) Suppression of nocturna plasma melatonin and 6-sulphatoxymelatonin by bright and dim light in man. Horm Metabol Res 19:437-440

65. Perras B, Meier M, Dodt C (2007) Light and darkness fail to regulate melatonin release in critically ill humans. Intensive Care Med 33:1954-1958

66. Verceles AC, Silhan L, Terrin M, Netzer G, Shanholtz C, Scharf SM (2012) Circadian rhythm disruption in severe sepsis: the effect of ambient light on urinary 6-sulfatoxymelatonin secretion. Intensive Care Med 38:804-810

67. Mclntyre IM, Norman TR, Burrows GD (1993) Alterations to plasma melatonin and cortisol after evening alprazolam administration in humans. Chronobiol Int 10:205-213

68. Parfitt AG, Klein DC (1976) Sympathetic nerve endings in the pineal gland protect against acute stress induced increase in N-acetyltransferase (EC 2.3.1.5.) activity. Endocrinology 99:840-851

69. Berlin I, Touitou Y, Guillemant S, Danjou P, Puech AJ (1995) Beta-adrenoceptor agonists do not stimulate daytime melatonin secretion in healthy subjects. Life Sci 56:325-331

70. Shilo L, Dagan Y, Smorjik Y, Weinberg U, Dolev S, Komptel B, Balaum H, Shenkman L (1999) Patients in the intensive care unit suffer from severe lack of sleep associated with loss of normal melatonin secretion pattern. Am J Med Sci 317:278-281

71. Zeitzer JM, Dijk D-J, Kronauer RE, Brown EN, Czeisler CA (2000) Sensitivity of the human circadian pacemaker to nocturnal light: melatonin phase resetting and suppression. J Physiol 526:695-702

72. Danilenko KV, Cajochen C, Wirz-Justice A (2003) Is sleep per se a zeitgeber in humans? J Biol Rhythms 18:170-178

73. Balan S, Leibovitz A, Zila SO, Ruth M, Chana W, Yassica B, Rahel B, Richard G, Neumann E, Blagman B, Habot B (2003) The relation between the clinical subtypes of delirium and the urinary level of 6-SMT. J Neuropsychiatry Clin Neurosci 15:363-366

74. Wu YH, Swaab DF (2007) Disturbance and strategies for reactivation of the circadian rhythm system in aging and Alzheimer's disease. Sleep Med 8(6):623-636

75. Lewis MC, Barnett SR (2004) Post-operative delirium: the tryptophan dyregulation model. Med Hypotheses 63:402-406

76. Duboule D (2003) Time for chronomics? Science 301:277

77. Halberg FE, Cornelissen G, Otsuka K, Schwartzkopff O, Halberg J, Bakken EE (2001) Chronomics. Biomed Pharmacother 55(1):153-190

78. Moser M, Schaumberger K, Schernhammer E, Stevens RG (2006) Cancer and rhythm. Cancer Causes Control 17:483-487 
79. Paskaloglu K, Sener G, Kapucu C, Ayanoglu-Dulger G (2004) Melatonin treatment protects against sepsis induced functional and biochemical changes in rat ileum and urinary bladder. Life Sci 74:1093-1104

80. Lin XJ, Mei GP, Liu J, Li YL, Zuo D, Liu SJ, Zhao TB, Lin MT (2011) Therapeutic effects of melatonin on heatstrokeinduced multiple organ dys-function syndrome in rats. J Pineal Res 50(4):436-444

81. Gitto E, Karbownik M, Reiter RJ, Tan DX, Cuzzocrea S, Chiurazzi P, Cordaro S, Corona G, Trimarchi G, Barberi I (2001) Effects of melatonin treatment in septic newborns. Pediatr Res 50:756-760

82. Tekbas OF, Ogur R, Korkmaz A, Kilic A, Reiter RJ (2008) Melatonin as an antibiotic: new insights into the action of this ubiquitous molecule. J Pineal Res 44:222-226

83. Li Z, Nickkholgh A, Yi X, Bruns H, Gross ML, Hoffmann K, Mohr E, Zorn M, Büchler MW, Schemmer P (2009) Melatonin protects kidney grafts from ischemia/reperfusion injury through inhibition of NF-kB and apoptosis after experimental kidney transplantation. J Pineal Res 46(4):365-372

84. Scheer FA, Van Montfrans GA, van Someren EJ, Mairuhu G, Buijs RM (2004) Daily nighttime melatonin reduces blood pressure in male patients with essential hypertension. Hypertension 43(2):192-197

85. Goncharuk VD, van Heerikhuize J, Dai JP, Swaab DF, Buijs RM (2001) Neuropeptide changes in the suprachiasmatic nucleus in primary hypertension indicate functional impairment of the biological clock. J Comp Neurol 431(3):320-330

86. Al-Aama T, Brymer C, Gutmanis I, Woolmore-Goodwin SM, Esbaugh J, Dasgupta M (2011) Melatonin decreases delirium in elderly patients: a randomized placebo-controlled trial. Int I Geriatr Psychiatry 26(7):687-694

87. Hatta K, Kishi Y, Wada K, Takeuchi T, Odawara T, Usui C, Kakamura H, for the DELIRIA-J Group (2014) Preventive effects of ramelteon on delirium: a randomized placebo-controlled trial. JAMA Psychiatry. doi:10.1001/ jamapsychiatry.2013.3320

88. Beauchamp D, Labrecque G (2007) Chronobiology and chronotoxicology of antibiotics and aminoglycosides. Adv Drug Deliv Rev 59:896-903

89. Chan M-C, Spieth PM, Quinn K, Parotto M, Zhang H, Slutsky AS (2012) Circadian rhythms: from basic mechanisms to the intensive care unit. Crit Care Med 40:246-253

90. Terman JS, Terman M (1999) Photopic and scotopic light detection in patients with seasonal affective disorder and control subjects. Biol Psychiatry 46:1642-1648

91. Cardinali DP, Brusco LI, Lloret SP, Furio AM (2002) Melatonin in sleep disorders and jet-lag. Neuroendocrinol Lett 3(Suppl 1):9-13

92. Bettermann H, von Bonin D, Fruhwirth M, Cysarz D, Moser M (2002) Effects of speech therapy with poetry on heart rate rhythmicity and cardiorespiratory coordination. Int J Cardiol 84:77-88

93. Kohsaka A, Bass J (2007) A sense of time: how molecular clocks organize metabolism. Trends Endocrinol Metab 18(1):4-11

94. Litinski M, Scheer FA, Shea SA (2009) Influence of the circadian system on disease severity. Sleep Med Clin 4(2):143-163

95. Castro R, Angus DC, Rosengart MR (2011) The effect of light on critical illness. Crit Care 15:218. doi: 10.1186/ cc10000

96. Ospina-Tascon GA, Buchele GL, Vincent JL (2008) Multicenter, randomized, controlled trials evaluating mortality in intensive care: doomed to fail? Crit Care Med 36:1311-1322

97. Poli-de-Figueiredo LF, Garrido AG, Nakagawa N, Sannomiya P (2008) Experimental models of sepsis and their clinical relevance. Shock 30(1):53-59

98. Angus DC, Mira JP, Vincent JL (2010) Improving clinical trials in the critically ill. Crit Care Med 38:527-532

99. Castanon-Cervantes O, Wu M, Ehlen JC, Paul K, Gamble KL, Johnson RL, Besing RC, Menaker M, Gewirtz AT, Davidson AJ (2010) Dysregulation of inflammatory responses by chronic circadian disruption. J Immunol 185 (10):5796-5805

100. Hadrich D (2006) Project Info: EUCLOCK-Entrainment of the Circadian Clock. http://www.euclock.org/index.php. Accessed 1 Jan 2006

101. Halberg F, Cornelissen G, Wilson D, Singh RB, De Meester F, Watanabe Y, Otsuka K, Khalilov E (2009) Chronobiology and chronomics: detecting and applying the cycles of nature. Biologist 56(4):209-214

102. Halberg F, Powell D, Otsuka K, Watanabe Y, Beaty LA, Rosch P, Czaplicki J, Hillman D, Schwartzkopff O, Cornelissen G (2013) Diagnosing vascular variability anomalies, not only MESOR-hypertension. Am J Physiol Heart Circ Physiol 305(3):279-294

103. Scheff JD, Calvano SE, Lowry SF, Androulakis IP (2010) Modeling the influence of circadian rhythms on the acute inflammatory response. J Theor Biol 264:1068-1076

doi:10.1186/2197-425X-2-18

Cite this article as: Papaioannou et al:: 'Chronomics' in ICU: circadian aspects of immune response and

therapeutic perspectives in the critically ill. Intensive Care Medicine Experimental 2014 2:18. 